TITLE:

\title{
Highly sensitive and selective mercury sensor based on mismatched base pairing with dioxT
}

\section{$\operatorname{AUTHOR}(\mathrm{S}):$}

Han, Ji Hoon; Hirashima, Shingo; Park, Soyoung; Sugiyama, Hiroshi

\section{CITATION:}

Han, Ji Hoon ...[et al]. Highly sensitive and selective mercury sensor based on mismatched base pairing with dioxT. Chemical Communications 2019, 55(69): $10245-$ 10248

ISSUE DATE:

2019-09-07

URL:

http://hdl.handle.net/2433/243835

\section{RIGHT:}

This is the accepted manuscript of the article, which has been published in final form at

https://doi.org/10.1039/c9cc05123f;; The full-text file will be made open to the public on 1 August 2020 in accordance with publisher's 'Terms and Conditions for Self-Archiving':, この論文は出版社版でありません。引用の際には出版社版 をご確認ご利用ください。; This is not the published version. Please cite only the published version. 


\section{COMMUNICATION}

Received 00th January 20xx, Accepted 00th January 20xx DOI: $10.1039 / x 0 \times x 00000 x$

\section{Highly sensitive and selective mercury sensor based on mismatched base pairing with ${ }^{\text {diox }} T$}

\author{
Ji Hoon Han, ${ }^{a}$ Shingo Hirashima, ${ }^{a}$ Soyoung Park, ${ }^{* a}$ and Hiroshi Sugiyama*a,b
}

\begin{abstract}
A highly selective and sensitive sensor for mercury was designed based on a new fluorescent nucleobase, dioxT. Its metal-sensing ability was investigated using mismatched dioxT-T and dioxT-C base pairing. The sensor exhibited a high sensitivity (quenching efficiency, 80\%, 1:1 binding mode) and selectivity upon the addition of mercury ions.
\end{abstract}

Heavy metal ions are well known for their involvement in important environmental issues, because of their severe effects on human health. ${ }^{1}$ In particular, the highly toxic mercury(II) ions are widespread pollutants that arise from industrial waste materials and a variety of natural sources. ${ }^{2-4}$ Although the mechanisms underlying the cytotoxicity and metabolic damage induced by mercury remain unclear, mercury(II) ions mainly cause several severe health problems, such as kidney failure, brain damage, and heart damage. ${ }^{1-}$ ${ }^{4}$ Since the first report of $\mathrm{T}-\mathrm{Hg}(\mathrm{II})-\mathrm{T}$ binding by Katz and the seminal studies of Ono and coworkers, ${ }^{5,6}$ the knowledge of the binding of mercury ions to T-T mismatched base pairs has led to the rapid development of metal sensors based on DNA. DNA is a very stable and highly programmable biomolecule that can provide a specific metal coordination site in a unique secondary structure. These features make DNA a very attractive material for the generation of metal-sensing devices. In this context, several mercury sensors have been developed based on single-nucleotide polymorphisms, ${ }^{7}$ nanomaterials, ${ }^{8,9}$ DNAzymes, ${ }^{10,11}$ and fluorescent nucleobases. ${ }^{12-15}$

Fluorescent nucleobase analogues are powerful and important tools in the chemical biology of nucleic acids, and their applications have enabled a variety of investigations, ${ }^{16-18}$ such as single-molecule polymorphism, ${ }^{19}$ monitoring of structural changes, ${ }^{20,21}$ elucidating enzyme activities, 22,23 and the development of the orientation-

a. Department of Chemistry, Graduate School of Science Kyoto University, Kitashirakawa-Oiwakecho, Sakyo-ku Kyoto 606-8502 (Japan)

E-mail: oleesy@kuchem.kyoto-u.ac.jp, hs@kuchem.kyoto-u.ac.jp

b. Institute for Integrated Cell-Material Science (iCeMS) Kyoto University, Yoshidaushinomiyacho Sakyo-ku Kyoto 606-8501 (Japan)

Electronic Supplementary Information (ESI) available: [details of any supplementary information available should be included here]. See DOI: 10.1039/x0xx00000x sensitive FRET system. ${ }^{24,25}$ Another advantage of fluorescent nucleobase analogues compared with conventional dyes, such as $\mathrm{Cy} 3$, Alexa dyes, FAM, and Texas Red, is that they are particularly useful to investigate the properties of the local structures of nucleic acids. Despite these advantages, the use of fluorescent nucleobase analogues and of their specific metal-binding interactions in the generation of metal sensors is relatively uncommon. A sensing system based on pyrrolo-dC (PdC) was reported in 2012; it was shown that the mismatched $\mathrm{PdC}-\mathrm{C}$ base pair can serve as a detector of silver ions. ${ }^{26} \mathrm{~A}$ few years later, a thymine-modified fluorescent nucleobase, DMAT, was reported as a fluorescent mercury detector, as DMAT-T was able to bind to mercury ions. ${ }^{27,28}$ Recently, it was also reported that the mismatched ${ }^{D M A} C-T$ base pair selectively binds to mercury and silver ions. ${ }^{29}$ Although these fluorescent nucleobase analogues exert a quenching effect in the presence of certain metal ions, their quenching efficiencies are not very high in the presence of 1 eq of a specific metal ion. Therefore, the development of a more effective metal-sensing system is warranted.
A

B
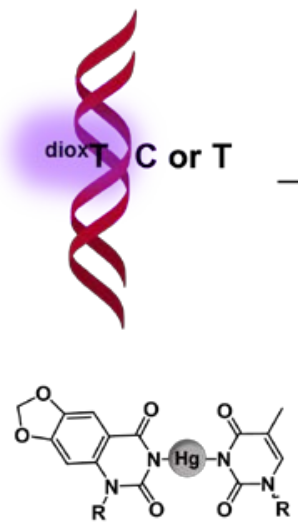

diox $\mathrm{T}-\mathrm{Hg}-\mathrm{T}$
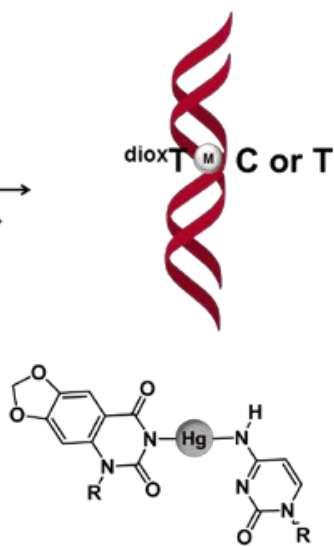

diox $\mathrm{T}-\mathrm{Hg}-\mathrm{C}$
Figure 1. (A) Schematic illustration of the metal sensors based on dioxT-C and dioxT-T mismatched base pairing that are used to detect mercury ions. (B) Metal-mediated base pairing of dioxT-Hg-T and dioxT$\mathrm{Hg}-\mathrm{C}$. 
Very recently, we developed new fluorescent thymine analogues based on the dioxoloquinazoline core, dioxT. diox $\mathbf{T}$ has desirable biophysical properties such as high brightness $\left(\Phi \varepsilon=3602 \mathrm{M}^{-1} \mathrm{~cm}^{-1}\right)$ and quantum yield (0.36) as a T surrogate, including complementary base pairing with $\mathrm{A}$. Moreover, dioxT-containing DNA displays an excellent quantum yield $(\sim 0.2)$ and a remarkable brightness $(\Phi \varepsilon=$ average $622 \mathrm{M}^{-1} \mathrm{~cm}^{-1}$ in double stranded DNA). ${ }^{30}$ The notable biophysical and photophysical features of diox instigated us to develop a fluorescent nucleic-acid-based metal sensor. Herein, we report the development of a highly sensitive and selective mercury sensor using a new fluorescent nucleobase analogue, dioxT.

diox $T$ was incorporated into the center of an 18-mer oligonucleotide (ODN1: 5'-CGTCCGTAXTACGCACGC-3', where $X=$ dioxT) via automatic solid-phase synthesis. Complementary strands containing matched or mismatched counter bases in the center (ODN1' $(\mathrm{Y}): 5^{\prime}-$ GCGTGCGTAYTACGGACG-3', where $Y=A, T, G, C$, and dioxT) were also prepared. We envisioned that mismatched base pairs containing diox $T$ can form the metallo base pairs dioxT-Hg-C and dioxT-Hg-T (Figure 1A). ${ }^{5,31-33}$ The binding of diox $\mathbf{T}-\mathrm{Hg}-\mathrm{T}$ could be characterized based on previous studies; the N3 nitrogen atoms of the dioxT-T mismatched base pair coordinate with mercury ions. In the case of diox $\mathbf{T}-\mathrm{Hg}-\mathrm{C}$, mercury ions coordinate with the N3 of diox $T$ and the N4 of cytosine (Figure 1B). ${ }^{27,31}$
A

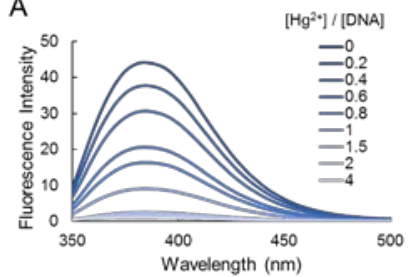

B

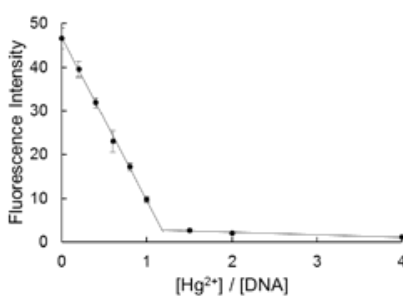

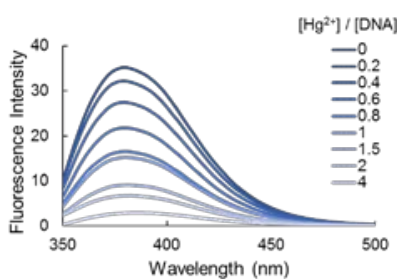

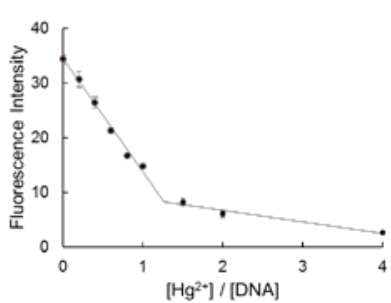

Figure 2. (A) Fluorescence spectra of the DNA-containing mismatched base pairs dioxT-T (left) and diox $\mathrm{T}-\mathrm{C}$ (right) upon titration of $\mathrm{HgCl}_{2}$. (B) Plot of fluorescence intensity based on the ratio of $\left[\mathrm{Hg}^{2+}\right]$ to [DNA]. ODN1 hybridized with $\mathrm{ODN1}^{\prime}(\mathrm{T})$ or $\mathrm{ODN1}^{\prime}(\mathrm{C})$. All samples contained $2 \mu \mathrm{M}$ DNA and $100 \mathrm{mM} \mathrm{NaNO}_{3}$ in $10 \mathrm{mM}$ MOPS buffer $(\mathrm{pH}$ 7.0). After the metal ions were added, the samples were incubated for $3 \mathrm{~h}$.

To confirm the effect of the mercury ion, we performed steadystate fluorescence measurements. Upon the addition of mercury ions, diox $\mathrm{T}$ mismatched with $\mathrm{C}$ and $\mathrm{T}$ showed high quenching efficiencies ( 70\%). In particular, a ratio of 1:1 binding between mercury ions and dioxT-T yielded a significant quenching efficiency
( $80 \%)$. This is the highest quenching efficiency to date compared with a previous system with DMAT-Hg-T that showed quenching efficiency $65 \% .{ }^{27}$ Remarkable brightness and great quantum yield ${ }^{30}$ as well as the highest quenching efficiency indicate the usefulness of diox $\mathbf{T}$ as a mercury sensor. Furthermore, the diox $\mathbf{T}$-diox $\mathbf{T}$ mismatched base pair also showed a high quenching efficiency $(60 \%)$, which was not greater than that of the mismatched dioxT-T base pair. The dioxT-A and diox T-G mismatched base pairs afforded a low quenching efficiency, which was considered as nonspecific binding of mercury to DNA. By gradually increasing the concentration of the $\mathrm{Hg}^{2+}$ ion, the fluorescence intensity of both the dioxT- $\mathrm{T}$ and diox $\mathrm{T}-\mathrm{C}$ mismatched base pairs decreased significantly between a $\left[\mathrm{Hg}^{2+} / \mathrm{DNA}\right]$ ratio of 0 and 1. After further addition of 1 eq of $\mathrm{Hg}^{2+}$ ion, we observed a low quenching effect, which was caused by nonspecific binding of mercury ions to DNA (Figure S1).

Table 1. Melting temperature $\left(T_{m}\right)$ of unmodified and modified duplexes in the absence and presence of 1 eq $\mathrm{Hg}^{2+}$ ions. ODN1 hybridized with $\mathrm{ODN1}^{\prime}(\mathrm{Y})$ (where $\mathrm{Y}=\mathrm{A}, \mathrm{T}, \mathrm{G}$, and $\mathrm{C}$ ). All sample contained $2 \mu \mathrm{M}$ DNA and $100 \mathrm{mM} \mathrm{NaClO}_{4}$ in $10 \mathrm{mM}$ MOPS buffer $(\mathrm{pH}$ 7.0). The sample was incubated for $3 \mathrm{~h}$ after the addition of the metal ions.

\begin{tabular}{ccccc} 
& \multicolumn{2}{c}{$\mathrm{X}=\mathrm{T}$} & \multicolumn{2}{c}{$\mathrm{X}=$ diox } \\
\hline $\mathrm{Y}$ & Without $\mathrm{Hg}^{2+}$ & With $\mathrm{Hg}^{2+}\left(\Delta \mathrm{T}_{\mathrm{m}}\right)$ & Without $\mathrm{Hg}^{2+}$ & With $\mathrm{Hg}^{2+}\left(\Delta \mathrm{T}_{\mathrm{m}}\right)$ \\
\hline $\mathrm{T}$ & 58.4 & $66.2(+7.8)$ & 59.8 & $65.0(+5.2)$ \\
\hline $\mathrm{C}$ & 56.6 & $60.1(+3.5)$ & 58.1 & $59.7(+1.6)$ \\
\hline $\mathrm{A}$ & 65.9 & $66.3(+0.4)$ & 64.5 & $64.4(-0.1)$ \\
\hline $\mathrm{G}$ & 59.2 & $60.0(+0.8)$ & 58.8 & $59.1(+0.3)$ \\
\hline
\end{tabular}

Based on quenching experiment with assumption of 1:1 binding stoichiometry, we calculated equilibrium binding affinities $\left(K_{d}\right)$ (Figure S6). At $25^{\circ} \mathrm{C}, \mathrm{K}_{d}$ values were obtained as $45 \mathrm{nM}$ for dioxT-T, and $106 \mathrm{nM}$ for dioxT-C, respectively. In previous report by Luedtke, $K_{d}$ values of DMAT-T and DMAT-C were $77 \mathrm{nM}$ and $152 \mathrm{nM}$, respectively. ${ }^{29}$ The results suggest that higher quenching efficiency of dioxT-Hg-T might be attributed to higher binding affinity of diox T.

As decreasing temperature at $5{ }^{\circ} \mathrm{C}, \mathrm{K}_{d}$ of dioxT-T to mercury ion is changed to $127 \mathrm{nM}$ and that of diox $\mathrm{T}-\mathrm{C}$ is varied to $59 \mathrm{nM}$. By plotting of $\Delta G$ versus temperature from $K_{d}$ values at $5{ }^{\circ} \mathrm{C}$ and $25^{\circ} \mathrm{C}, \Delta S$ of diox $T$ $\mathrm{T}$ and dioxT-C show $260 \mathrm{Jmol}^{-1}$ and $66 \mathrm{Jmol}^{-1}$. These results were consistent with previous report on DMAT by Luedtke, ${ }^{29}$ indicating that diox $\mathrm{T}-\mathrm{C}$ is less water released from mercury binding to mismatched base pair rather than dioxT-T mismatched base pair. We also measured the time-resolved fluorescence of duplexes with dioxT-T and diox $\mathrm{T}-\mathrm{C}$ mismatched base pairs. In absence of mercury ion, both of dioxT-C and dioxT-T mismatched base pair show biexponential fluorescence decay curves (Figure S8 and Table S1). The short lifetime is attributed by stacking interaction between diox $\mathbf{T}$ and nearest neighboring bases and long lifetime comes from unstacked dioxT. Upon addition of 1 eq mercury ion, the average lifetime of dioxT$\mathrm{T}$ mismatched base pair decrease from $3.47 \mathrm{~ns}$ to $2.92 \mathrm{~ns}$, while that of dioxT-Hg-C mismatched base pair did not change ( $2.33 \mathrm{~ns})$. Upon addition of 2 eq mercury ion, both dioxT-T and diox $\mathbf{T}-\mathrm{C}$ mismatched 
base pair resulted in decreased average lifetimes ( $\tau 1$ and $\tau 2$ ) and the extended lifetime $(\tau 3)$ that can be explained by the high spin-orbit coupling associated with the heavy metal ion. ${ }^{35}$ These results suggest that dioxT-C mismatched base pair has different metal binding behavior from that of dioxT-T base pair. Further investigation is underway to understand the interaction between mercury ion and dioxT at the molecular level. 39

To investigate the stabilization of mismatched base pairs containing diox $T$ in the presence of mercury ions, we performed melting temperature measurements (Table 1 and Figure S9). The thermal stabilities of duplexes with the A-dioxT or G-diox T pair were slightly lower than those of unmodified duplexes with A-T or G-T. Regarding the latter, the addition of mercury ions did not affect much the thermal stabilities of the duplexes. Consistent with previous studies, the melting temperature of duplexes containing mismatched base pairs with dioxT (dioxT-C and dioxT-T) was higher than that of unmodified duplexes with a mismatched pair (T-C and T-T) without metal ions. In

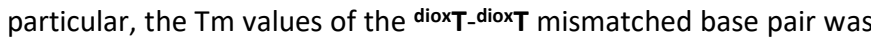
significantly higher $\left(\mathrm{Tm}=63.6^{\circ} \mathrm{C}\right)$ than that of the T-T mismatched base pair $\left(\mathrm{Tm}=58.4{ }^{\circ} \mathrm{C}\right)$. This may have been caused by the high stacking property of diox T. After the addition of mercury ions, the thermal stability of duplexes containing T-T or diox T-T increased significantly ( $\Delta \mathrm{Tm}$ of T-T $=+7.8^{\circ} \mathrm{C}$ and $\Delta \mathrm{Tm}$ of dioxT-T $=+5.2^{\circ} \mathrm{C}$ ), as expected. Interestingly, the $\mathrm{Tm}$ values of duplexes containing diox $\mathbf{T}$ dioxT and dioxT-T mismatched base pairs were similar to that of the native T-T mismatched base pair upon the addition of mercury ions. This may be because the coordination of the mercury ion with the N3 of the thymine moiety rearranges the location of diox $\mathrm{T}$ between the nearest neighboring bases, resulting in a thermal stability that is similar to that of native T. Duplexes with T-C or dioxT-C mismatched pairs also showed a slightly increased thermal stability $(\Delta \mathrm{Tm}$ of $\mathrm{T}-\mathrm{C}=$ $+3.5^{\circ} \mathrm{C}$ and $\Delta \mathrm{Tm}$ of diox $\mathrm{T}-\mathrm{C}=+1.6^{\circ} \mathrm{C}$ ) in the presence of mercury ions. Our $\mathrm{T}_{\mathrm{m}}$ results are consistent with those of previous reports that showed that the T-T and T-C mismatched base pairs are highly selective for $\mathrm{Hg}^{2+}$ ions. ${ }^{32-34}$ We also performed $\mathrm{CD}$ measurements (Figure S10). Upon addition of 1 eq of $\mathrm{Hg}^{2+}$ ion, dioxT-T and diox $\mathrm{T}-\mathrm{C}$ did not change the global structures of duplexes. This indicates that this sensing system based on a fluorescent nucleobase analogue, dioxT, can be a powerful tool in the investigation of local structural changes without deformation of the global structure.

To verify whether metal-binding selectivity is a useful sensing system, we performed a metal screening using a mismatched base pair containing diox T-T. The fluorescence of the diox T-T mismatched base pair indicates the presence of a high quenching efficiency exclusively for the mercury ions; in contrast, an additional nine metal ions, i.e., $\mathrm{Ag}^{+}, \mathrm{Co}^{2+}, \mathrm{Ca}^{2+}, \mathrm{Cu}^{2+}, \mathrm{Mg}^{2+}, \mathrm{Ni}^{2+}, \mathrm{Zn}^{2+}, \mathrm{Cd}^{2+}$, and $\mathrm{Pb}^{2+}$, displayed no quenching effect. The dioxT-C mismatched base pair also exhibited a high quenching efficiency with mercury ions. Regarding the dioxT-C mismatched base pair, fluorescence quenching was observed in the presence of silver ions, albeit at a lower level ( 30\%) than that of mercury ions. ${ }^{40}$ Other metal ions, with the exception of mercury and silver ions, did not afford fluorescence quenching for the diox $\mathbf{T}-\mathrm{C}$ mismatched base pair. These results indicate that diox $\mathbf{T}$ is very sensitive for the detection of specific metal ions. Furthermore,

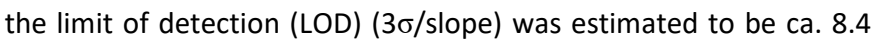
$\mathrm{nM}$ for dioxT-Hg-T and ca. $17.1 \mathrm{nM}$ for diox $\mathrm{T}-\mathrm{Hg}-\mathrm{C}$, respectively (Figure S11). These values are comparable to previous mercury sensors based on DNA functionalized chemosensors. ${ }^{36-38}$ It is noteworthy that LOD of dioxT-Hg-T is lower than $10 \mathrm{nM}$, the allowable value of $\mathrm{Hg}^{2+}$ in drinking water by Environmental Protection Agency (EPA) regulation.

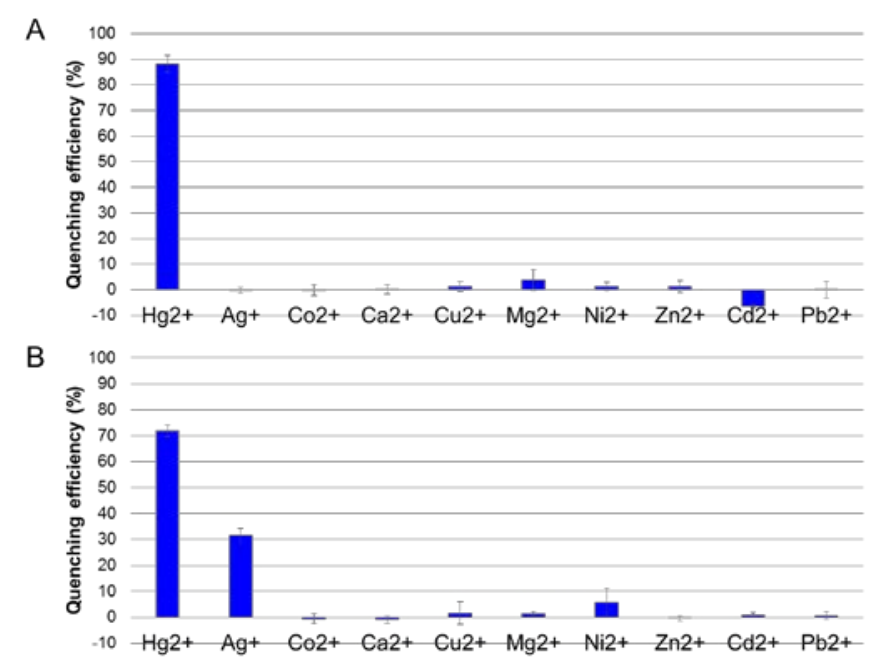

Figure 3. (A) Fluorescence selectivity of the DNA-containing mismatched dioxT-T base pair or (B) mismatched dioxT-C base pair after the addition of various metal ions $(2 \mu \mathrm{M})$. All samples contained 2 $\mu \mathrm{M}$ DNA and $100 \mathrm{mM} \mathrm{NaNO}_{3}$ in $10 \mathrm{mM}$ MOPS buffer ( $\mathrm{pH}$ 7.0). The sample was incubated for $3 \mathrm{~h}$ after the addition of the metal ions.

In summary, we report a mercury sensor that was generated using a new size expanded fluorescent nucleobase, dioxT. The dioxT-T and dioxT-C mismatched base pairs induced a strong fluorescencequenching effect after binding to mercury ions. The results presented here clearly indicate that the diox $\mathrm{T}-\mathrm{T}$ and diox $\mathrm{T}-\mathrm{C}$ mismatched base pairs in duplexes can serve as a nucleic-acid-based mercury sensor. Moreover, the dioxT-C base pair may be used as a detector of silver ions. To our knowledge, the dioxT-based system has the highest fluorescence-quenching efficiency for mercury ions compared with existing metal sensors using fluorescent nucleobases reported to date. Furthermore, we believe that this system can provide deeper insights for the study of the kinetics and dynamics of nucleic acids that are affected by specific metal ions, such as the $\mathrm{Hg}^{2+}$ ion.

\section{Acknowledgment}

We express sincere thanks for a Grant-in-Aid Priority Research from Japan Society for the Promotion of Science (JSPS). We also thank KAKENHI program (Grant-in-Aid for scientific research C) for support to S. P. We like to thank Karin Nishimura (Graduate School of Engineering, Kyoto University) for technical assistance to measure mass spectra of synthetic compounds. 


\section{Notes and references}

1 Renzoni, F. Zino, E. Franchi, Environ. Res., 1998, 77, 68-72.

2 A. Stacchiotti, F. Morandini, F. Bettoni, I. Schena, A. Lavazza, P. G. Grigolato, P. Apostoli, R. Rezzani, M. F. Aleo, Toxicology, 2009, 264, 215-224.

3 P. B. Tchounwou, W. K. Ayensu, N. Ninashvili, D. Sutton, Environmental Toxicology: An International Journal, 2003, 18, 149-175.

4 O. Malm, Environ. Res., 1998, 77, 73-78.

5 Y. Miyake, H. Togashi, M. Tashiro, H. Yamaguchi, S. Oda, M. Kudo, Y. Tanaka, Y. Kondo, R. Sawa, T. Fujimoto, J. Am. Chem. Soc., 2006, 128, 2172-2173

6 S. Katz, Biochim. Biophys. Acta, 1963, 68, 240-253.

7 Y. Lin, H. Ho, C. Huang, H. Chang, Nucleic Acids Res., 2008, 36, e123-e123.

8 B. Ye, B. Yin, Angew. Chem. Int. Ed., 2008, 47, 8386-8389.

9 H. Wang, Y. Wang, J. Jin, R. Yang, Anal. Chem., 2008, 80, $9021-$ 9028.

10 J. Liu, Y. Lu, Angew. Chem. Int. Ed., 2007, 46, 7587-7590.

11 T. Li, S. Dong, E. Wang, Anal. Chem., 2009, 81, 2144-2149.

12 S. J. Kim, E. T. Kool, J. Am. Chem. Soc., 2006, 128, 6164-6171.

13 A. Dumas, N. W. Luedtke, Chem. Eur. J., 2012, 18, 245-254.

14 S. K. Jana, X. Guo, H. Mei, F. Seela, Chem. Comm., 2015, 51, 17301-17304.

15 J. N. Wilson, E. T. Kool, Org. Biomol. Chem., 2006, 4, 42654274.

16 A. Okamoto, Y. Ochi, I. Saito, Bioorg. Med. Chem. Lett., 2005, 15, 4279-4281.

17 L. M. Wilhelmsson, Q. Rev. Biophys., 2010, 43, 159-183.

18 R. W. Sinkeldam, N. J. Greco, Y. Tor, Chem. Rev., 2010, 110, 2579-2619.

19 A. Okamoto, K. Tanaka, T. Fukuta, I. Saito, J. Am. Chem. Soc. 2003, 125, 9296-9297.

20 S. Yamamoto, S. Park, H. Sugiyama, RSC Adv., 2015, 5, 104601 104605.

21 S. Park, H. Otomo, L. Zheng, H. Sugiyama, Chem. comm., 2014 50, 1573-1575.

22 H. Otomo, S. Park, S. Yamamoto, H. Sugiyama, RSC Adv., 2014, 4, 31341-31344.

23 I. Okamura, S. Park, R. Hiraga, S. Yamamoto, H. Sugiyama, Chem. Lett., 2016, 46, 245-248.

24 J. H. Han, S. Yamamoto, S. Park, H. Sugiyama, Chem. Eur. J., 2017, 23, 7607-7613.

25 J. H. Han, S. Park, F. Hashiya, H. Sugiyama, Chem. Eur. J., 2018 , 24, 17091-17095.

26 K. S. Park, J. Y. Lee, H. G. Park, Chem. Comm., 2012, 48, 45494551.

27 G. Mata, O. P. Schmidt, N. W. Luedtke, Chem. Commun., 2016, 52, 4718-4721.

28 O. P. Schmidt, G. Mata, N. W. Luedtke, J. Am. Chem. Soc., 2016, 138, 14733-14739.

29 O. P. Schmidt, A. S. Benz, G. Mata, N. W. Luedtke, Nucleic Acids Res., 2018, 46, 6470-6479.

30 S. Hirashima, J. H. Han, H. Tsuno, Y. Tanigaki, S. Park, H. Sugiyama, Chem. Eur. J., Accepted DOI 10.1002/chem. 201900843

31 H. Liu, C. Cai, P. Haruehanroengra, Q. Yao, Y. Chen, C. Yang, Q. Luo, B. Wu, J. Li, J. Ma, J. Sheng, J. Gan, Nucleic Acids Res., 2017, 45, 2910-2918.

32 H. Torigoe, A. Ono, T. Kozasa, Chem. Eur. J., 2010, 16, 1321813225

33 J. Kondo, T. Yamada, C. Hirose, I. Okamoto, Y. Tanaka, A. Ono, Angew. Chem. In. Ed., 2014, 53, 2385-2388.

34 A. Ono, H. Torigoe, Y. Tanaka, I. Okamoto, Chem. Soc. Rev., 2011, 40, 5855-5866.
35 E. Baggaley, S. W. Botchway, J. W. Haycock, H. Morris, I. V. Sazanovich, J. G. Williams, J. A. Weinstein, Chem. Sci., 2014, 5, 879-886.

36 L. Deng, Z. Zhou, S. J. Dong, Chem. Comm., 2011, 47, 1106511067

37 L. Q. Guo, H. Hu, R. Q. Sun and G. A. Chen, Talanta, 2009, 79, 775-779.

38 C. A. Mirkin and J. S. Lee, Anal. Chem., 2008, 80, 6805-6808.

39 H. Miyachi, T. Matsui, Y. Shigeta and K. Hirao, Phys. Chem. Chem. Phys, 2010, 12, 909-917.

40 Unlike mercury ion, fluorescence intensity decreased significantly after addition of over 2 eq of silver ion (Figure S3). The fluorescence of duplexes with dioxT-A matched base pair did not change by silver ion (Figure S4), suggesting that nonspecific binding of silver ion is probably not main cause of fluorescence quenching in the presence of greater than 1 eq of $\mathrm{Ag}(\mathrm{I})$ ion. $\mathrm{CD}$ spectra of dioxT-C mismatched base pair upon the titration of silver ion showed the decreased magnitude at $255 \mathrm{~nm}$ with red-shifted the highest positive band from 280 $\mathrm{nm}$ to $285 \mathrm{~nm}$ (Figure S5). These results suggest that excess amount of silver ion induce local structure change of DNA and this can affect fluorescence intensity of dioxT-C. Further investigation is underway to understand the different quenching efficiency between mercury ion and silver ion. 